\title{
Pulmonary Outcomes of Early Extubation in Extremely Premature Infants (Gestational Age: 25-26 Weeks) with Synchronized Nasal Intermittent Positive-Pressure Ventilation
}

Eun Mi Choi, M.D., Jae Hyun Park, M.D., Chun Soo Kim, M.D., and Sang Lak Lee, M.D. Department of Pediatrics, Keimyung University Dongsan Medical Center, Deagu, Korea

\section{ABSTRACT}

Purpose: To investigate the pulmonary outcomes of early extubation (within the first 24 hours of life) with synchronized nasal intermittent positive pressure ventilation (NIPPV) in extremely premature infants born at 25-26 weeks' gestation.

Methods: Medical records of extremely premature infants (gestational age: 25-26 weeks) born and admitted to the Keimyung University Dongsan Medical Center between January 2015 and December 2015 ( $n=42)$ were reviewed retrospectively. The early extubation group included infants who were extubated within the first 24 hours of life and was compared with a control group that included infants who remained ventilated beyond the first 24 hours of life. Extubation failure was defined as the need for reintubation within 72 hours after extubation.

Results: Of the 35 enrolled infants, 22 (62.9\%) were extubated within the first 24 hours of life. No significant differences in perinatal factors were observed between the early extubation and control groups. Between the two groups, the incidence rates of extubation failure (18.2\% [4/22] vs. 7.7\% [1/13], $P=0.39)$, reintubation (50.0\% [11/ $22]$ vs. $46.2 \%$ [6/13], $P=0.84)$, mortality ( $18.2 \%$ [4/22] vs. $15.4 \%$ [2/13], $P=0.83)$, and the combined rates of clinical bronchopulmonary dysplasia (BPD) or death $(40.9 \%$ [9/22] vs. $38.5 \%$ [5/13], $P=0.89$ ) did not significantly differ.

Conclusion: Early extubation (within the first 24 hours of life) with synchronized NIPPV is safe and effective in the extremely premature infants born at 25-26 weeks' gestation, and does not indicate increased risks of extubation failure and other morbidities.

Key Words: Extremely premature infants, Noninvasive ventilation

\section{INTRODUCTION}

Surfactant replacement and invasive mechanical ventilation are used to treat respiratory
Received: 18 March 2016

Revised: 4 May 2016

Accepted: 5 May 2016

Correspondence to: Jae Hyun Park Department of Pediatrics, Dongsan Medical Center, Keimyung University School of Medicine, 56 Dalseong-ro, Jung-gu, Daegu 41931, Korea

Tel: +82-53-250-7524

Fax: +82-53-250-7783

E-mail: jhpark.neo@gmail.com

Copyright(c)

By Korean Society of Neonatology.

All right reserved.

This is an Open-Access article distributed under the terms of the Creative Commons Attribution Non-Commercial License (http://creativecommons.org/licenses/ by-nc/4.0), which permits unrestricted non-commercial use, distribution, and reproduction in any medium, provided the original work is properly cited. 
distress syndrome (RDS) in premature infants. Although surfactant replacement in premature infants decreased the incidence of bronchopulmonary dysplasia (BPD) ${ }^{1)}$, persistent invasive mechanical ventilation after surfactant replacement is the major risk factor of $\mathrm{BPD}^{2)}$. Early surfactant administration followed by extubation involving nasal continuous positive airway pressure (NCPAP) or nasal intermittent positive pressure ventilation (NIPPV) has been shown to decrease the incidence of BPD in very low birth weight infants (VLBWI) in observational studies ${ }^{3,4)}$, and minimized the need for mechanical ventilation via endotracheal tube in the first week of life ${ }^{5,6)}$.

NIPPV is a noninvasive mode of ventilation that uses a nasal interface that augments the infant's spontaneous breath efforts by providing a backup rate ${ }^{7,8)}$. It is effective in premature infants who require respiratory support, as it reduces the incidence of premature apnea and atelectasis, and improves ventilationperfusion matching while decreasing extubation failures ${ }^{9-13)}$. The incidence of BPD was also reduced in infants managed by NIPPV $^{14-16)}$. In comparison with NCPAP, NIPPV reduced the need for endotracheal ventilation in premature infants with early extubation after receiving early surfactant for $\mathrm{RDS}^{6,17)}$.

Synchronized NIPPV can improve chest wall stability and pulmonary mechanics by decreasing thoracoabdominal motion asynchrony ${ }^{18)}$, increasing flow delivery by increasing the peak inspiratory pressure (PIP) to higher than the positive endexpiratory pressure (PEEP) ${ }^{9)}$, increasing tidal and minute volumes $^{19)}$, and decreasing work of breathing ${ }^{20)}$.

Although some studies from Korea investigated the therapeutic effect of NIPPV or CPAP in premature infants ${ }^{21,22)}$, studies on extremely premature infants are limited. In this study, we aimed to investigate the pulmonary outcomes of early airway extubation (within the first 24 hours of life) with synchronized NIPPV in extremely premature infants born at 25-26 weeks' gestation.

\section{MATERIALS AND METHODS}

We retrospectively reviewed the medical records of 42 extremely premature infants born at 25-26 weeks' gestation who were admitted to the neonatal intensive care unit (NICU) of Keimyung University Dongsan Medical Center between January and December 2015. Two infants with perinatal asphyxia (Apgar score at $5 \mathrm{~min} \leq 3$ ), three infants with perinatal infection, and two infants who were transferred to another hospital were excluded.

All the infants received cardiopulmonary resuscitation in the delivery room according to the Neonatal Resuscitation Program (NRP) by the American Academy of Pediatrics and the American Heart Association ${ }^{23)}$. Endotracheal intubation was immediately performed upon delivery, and an exogenous surfactant (Curosurf', Chiesi Pharmaceuticals, Parma, Italy) was immediately administered as part of prophylactic therapy at a dose of $200 \mathrm{mg} / \mathrm{kg}$. The second dose of the exogenous surfactant was administered to infants who had persistent respiratory distress and received ventilator care without decreased mean airway pressure or oxygen requirement at 6 hours after the initial dose. The ventilator was set in the synchronized intermittent mandatory ventilation (SIMV) mode to facilitate weaning from the mechanical ventilator. The criteria for extubation were as follows: PIP $<15 \mathrm{cmH}_{2} \mathrm{O}$; PEEP $<7 \mathrm{cmH}_{2} \mathrm{O}$; intermittent man datory ventilator rate $<15$ breaths per minute; and fraction of inspired oxygen $\left(\mathrm{FiO}_{2}\right)<0.3$, which were not differ from those in other studies $^{9-11,13)}$. Caffeine citrate (Neocaf ${ }^{\circledR}$, loading dose, 20 $\mathrm{mg} / \mathrm{kg}$ ) was intravenously administrated before extubation. The decision to extubate within the within the first 24 hours of life or to continue with mechanical ventilation was at the attending neonatologist's discretion.

After airway extubation, nasal respiratory support was provided via a nasal prong by using the Medijet NCPAP System (MedinMedical Innovations GmbH, Puchheim, Germany), which was set in the synchronized NIPPV mode. During synchronized NIPPV, PIP was started at 10-15 $\mathrm{cmH}_{2} \mathrm{O}$, PEEP was set at 6-9 $\mathrm{cmH}_{2} \mathrm{O}$, inspiratory time was set at $0.6 \mathrm{~s}$, and the backup or mandatory rate was set between 20 and 30 breaths per minute. The $\mathrm{FiO}_{2}$ was adjusted to maintain $\mathrm{SpO}_{2}$ at $88-95 \%$.

The early extubation group, which included infants extubated within the first 24 hours of life, was compared with the control group, which included infants who remained ventilated beyond the first 24 hours of life. Extubation failure was defined as the need for reintubation within 72 hours after extubation. The criteria were as follows: respiratory acidosis $\left(\mathrm{PaCO}_{2}>65\right.$ mmHg of two consecutive blood gases); $\mathrm{FiO}_{2}>0.4$ to maintain $\mathrm{SpO}_{2}$ at 88-95\%; and apnea episodes that required bag/mask ventilation $^{24)}$.

The following variables were analyzed for the perinatal factors: gestational age (GA), birth weight (BW), delivery mode, sex, multiple gestation, antenatal steroid use, pregnancy-induced hypertension $(\mathrm{PIH})$, preterm premature rupture of membrane 
(PPROM), oligohydramnios, and Apgar score at $5 \mathrm{~min}$.

The outcomes after airway extubation were characterized by the rates of extubation failure, the need for endotracheal ventilation at 7 days of age, reintubation, pulmonary hemorrhage, air leak syndrome, intraventricular hemorrhage (IVH) grade $\geq 3^{25}$, patent ductus arteriosus (PDA) treated with ibuprofen or surgical ligation, necrotizing enterocolitis (NEC) modified Bell's stage $>$ II, pneumoperitoneum detected on abdominal radiography, bowel perforation detected on explorative laparotomy, mortality, and combined rates of clinical BPD or death.

Among survived infants, the neonatal morbidities during hospitalization included days on endotracheal ventilation, days on nasal respiratory support, days on supplemental oxygen via a nasal prong without positive pressure support, days on total parenteral nutrition (TPN), clinical BPD, postnatal dexame thasone use for BPD prevention, and retinopathy of prematurity (ROP) requiring treatment. Clinical BPD was defined as the need for supplemental oxygen or positive pressure support at 36 weeks postmenstrual age ${ }^{26)}$.

\section{Statistical analyses}

SPSS ver. 20.0 (SPSS Inc., Chicago, IL, USA) was used for the statistical analyses. Perinatal factors, variables associated with acute pulmonary outcomes and neonatal morbidities were compared between the two groups by using the Student's $t$-test and Fisher exact test. A $P$-value $<0.05$ was considered statistically significant.

\section{RESULTS}

Of the 35 infants, 22 (62.9\%) were extubated within the first 24 hours after birth. The mean time to airway extubation was $18.8 \pm 3.4$ hours in the early extubation group and $40.5 \pm 27.7$ hours in the control group.

The comparison of the perinatal factors between the early extubation and control groups is shown in Table 1 . No significant differences in GA, BW, delivery mode, sex, multiple gestation, antenatal steroid use, PIH, PPROM, oligohydramnios, and Apgar score at $5 \mathrm{~min}$ were observed between the two groups.

The outcomes after airway extubation are shown in Table 2. The incidence of extubation failure in the early extubation group $(18.2 \%, 4 / 22)$ was higher than that in the control group (13.3\%, 2/15), but the difference was not statistically significant
$(P=0.69)$. In terms of the need for endotracheal ventilation at 7 days of age, no significant difference was found between the two groups (31.8\% [7/22] vs. $7.7 \%$ [1/13], $P=0.10)$. Of the 35 enrolled infants, 17 (48.6\%) required reintubation during hospitalization. PDA ligation was performed in 13 infants and was the most common cause of reintubation. Exploratory laparotomy, the second common cause of reintubation, was performed in 6 infants because of pneumoperitoneum. Bowel perforation was not detected in 2 of 6 infants who underwent exploratory laparotomy. Reintubation derived from compression of the nasal septum by the nasal prongs was not developed. Between the two groups, no significant differences were found in the mortality (18.2\% [4/22] vs. $15.4 \%$ [2/13], $P=0.83$ ), and the combined rates of clinical BPD or death $(40.9 \%$ [9/22] vs. $38.5 \%$ [5/13], $P=0.89)$. The incidence of other neonatal morbidities also did not significantly differ between the two groups $(P>0.05)$.

Among survived infants, the neonatal morbidities during hospitalization are shown in Table 3. The time on endotracheal ventilation in the early extubation group (6.1 \pm 8.5 days) was longer than that in the control group (4.0 \pm 3.2 days), but the difference was not statistically significant $(P=0.44)$. The times on nasal respiratory support and supplemental oxygen without positive pressure support were not significantly different between the two groups ( $P>0.05)$. Between the two groups, no significant differences were found in the rates of clinical BPD (27.8\% [5/18] vs. $27.35 \%$ [3/11], $P=0.98)$ and postnatal dexamethasone use for BPD prevention (44.4\% [8/18] vs. 54.5\% [6/11], $P=0.67)$.

Table 1. Comparison of the Perinatal Factors between the Early Extubation and Control Groups

\begin{tabular}{lccc}
\hline & $\begin{array}{c}\text { Early extubation } \\
(\mathrm{n}=22)\end{array}$ & $\begin{array}{c}\text { Control } \\
(\mathrm{n}=13)\end{array}$ & $P$-value \\
\hline Gestational age (wk) & $25.6 \pm 0.5$ & $25.4 \pm 0.7$ & 0.42 \\
Birth weight (g) & $874 \pm 116$ & $839 \pm 143$ & 0.44 \\
C-sec, n (\%) & $22(100 \%)$ & $12(92.3 \%)$ & 0.19 \\
Male, n (\%) & $15(68.2 \%)$ & $6(40.0 \%)$ & 0.09 \\
Multiple gestation, n (\%) & $4(18.2 \%)$ & $3(23.1 \%)$ & 0.73 \\
Antenatal steroid use, n (\%) & $21(95.5 \%)$ & $13(100 \%)$ & 0.44 \\
PROM, n (\%) & $12(54.5 \%)$ & $9(69.2 \%)$ & 0.39 \\
PIH, n (\%) & $2(9.1 \%)$ & 0 & 0.26 \\
Oligohydroamnios, n (\%) & $3(13.6 \%)$ & $2(15.4 \%)$ & 0.89 \\
Apgar score, 5 min & $7.5 \pm 0.6$ & $7.3 \pm 0.9$ & 0.55 \\
\hline
\end{tabular}

Plus-minus values are mean \pm SD.

Abbreviations: PPROM, preterm premature rupture of membrane; $\mathrm{PIH}$, pregnancy-induced hypertension. 
Table 2. Comparison of the Neonatal outcomes after Airway Extubation

\begin{tabular}{|c|c|c|c|}
\hline & Early extubation $(n=22)$ & Control $(n=13)$ & $P$-value \\
\hline Time to extubation (hr) & $18.8 \pm 3.4$ & $40.5 \pm 27.7$ & 0.02 \\
\hline Extubation failure, n (\%) & $4(18.2 \%)$ & $1(7.7 \%)$ & 0.39 \\
\hline Reintubation, n (\%) & $11(50.0 \%)$ & $6(46.2 \%)$ & 0.84 \\
\hline Endotracheal ventilation at 7 days of age, $\mathrm{n}(\%)$ & $7(31.8 \%)$ & $1(7.7 \%)$ & 0.10 \\
\hline Air leak syndrome, n (\%) & $1(4.5 \%)$ & $2(15.4 \%)$ & 0.27 \\
\hline Pulmonary hemorrhage, n (\%) & $2(9.1 \%)$ & $1(7.7 \%)$ & 0.89 \\
\hline IVH grade $\geq 3, \mathrm{n}(\%)$ & $1(4.5 \%)$ & $1(7.7 \%)$ & 0.70 \\
\hline PDA reqiuring treatment, $\mathrm{n}(\%)$ & $13(59.1 \%)$ & $9(69.2 \%)$ & 0.55 \\
\hline NEC (Modified Bell's Stage $\geq \mathrm{II}), \mathrm{n}(\%)$ & $4(18.2 \%)$ & $3(23.1 \%)$ & 0.79 \\
\hline Pneumoperitoneum, n (\%) & $5(22.7 \%)$ & $1(7.7 \%)$ & 0.25 \\
\hline Bowel perforation, $\mathrm{n}(\%)$ & $3(13.6 \%)$ & $1(7.7 \%)$ & 0.59 \\
\hline Mortality, n (\%) & $4(18.2 \%)$ & $2(15.4 \%)$ & 0.83 \\
\hline Clinical BPD* or death, n (\%) & $9(40.9 \%)$ & $5(38.5 \%)$ & 0.89 \\
\hline
\end{tabular}

Plus-minus values are mean \pm SD.

${ }^{*}$ Clinical BPD was defined as the need for supplemental oxygen or positive pressure support at 36 weeks postmenstrual age.

Abbreviations: IVH, intraventricular hemorrhage; PDA, patent ductus arteriosus; NEC, necrotizing enterocolitis; BPD, bronchopulmonary dysplasia.

Table 3. Among Survived Infants, Neonatal Morbidities during Hospitalization

\begin{tabular}{|c|c|c|c|}
\hline & Early extubation $(n=18)$ & Control $(n=11)$ & $P$-value \\
\hline Days on endotracheal ventilation & $6.1 \pm 8.5$ & $4.0 \pm 3.2$ & 0.44 \\
\hline Days on nasal respiratory support & $60.1 \pm 11.0$ & $56.6 \pm 16.6$ & 0.51 \\
\hline Days on supplemental oxygen without positive respiratory support & $0.1 \pm 0.4$ & 0 & 0.45 \\
\hline Supplemental oxygen or positive pressure support at 28 days of age, $n(\%)$ & $18(100 \%)$ & $10(90.9 \%)$ & 0.19 \\
\hline Days on TPN & $38.5 \pm 23.7$ & $42.5 \pm 29.6$ & 0.70 \\
\hline Clinical BPD*, n (\%) & $5(27.8 \%)$ & $3(27.3 \%)$ & 0.98 \\
\hline Postnatal dexamethasone use for BPD prevention, $\mathrm{n}(\%)$ & $8(44.4 \%)$ & $6(54.5 \%)$ & 0.67 \\
\hline ROP requiring treatment, $\mathrm{n}(\%)$ & $3(16.7 \%)$ & $1(9.1 \%)$ & 0.57 \\
\hline
\end{tabular}

Plus-minus values are mean \pm SD.

* Clinical BPD was defined as the need for supplemental oxygen or positive pressure support at 36 weeks postmenstrual age.

Abbreviations: TPN, total parenteral nutrition; BPD, bronchopulmonary dysplasia; ROP, retinopathy of prematurity.

\section{DISCUSSION}

The rate of early extubation (within the first 24 hours of life) using synchronized NIPPV was 59.5\%, and the rate of successful early extubation without extubation failure was $81.8 \%$. Our data support the application of early extubation (within the first 24 hours of life) with synchronized NIPPV, which indicate a success rate that exceeds the previously reported rates ${ }^{27,28)}$. Al Faleh et al. reported that the rate of early extubation (in the first 48 hours of life) with CPAP in extremely low birth weight infants (ELBWI) was $32 \%$ and that the rate of successful extubation was $80 \%{ }^{28)}$. In other previous trials, the rates of extubation failure with NIPPV were reported to range from $5 \%$ to $15 \%$ in $\mathrm{VLBWI}^{6,9-11)}$.

Ramanathan et al. ${ }^{6}$ reported that $17 \%$ of infants born at 26 29 weeks' gestation needed endotracheal ventilation at 7 days of age in the NIPPV group. Because of lower gestational age in the present study, it might be associated with the higher rates in the need for endotracheal ventilation at 7 days of age.

Fluctuating cerebral blood flow (CBF) is associated with the development of $\mathrm{IVH}^{29,30)}$. High $\mathrm{PCO}_{2}$ levels have been associated with the development of IVH, which contributes to the fluctuating $\mathrm{CBF}^{31,32)}$. However, in a recent multicenter study ${ }^{33)}$, permissive hypercapnia did not increase the risk of IVH. In the present study, we targeted the maintenance of capillary $\mathrm{PCO}_{2}$ levels $\leq 65 \mathrm{mmHg}$. The incidence of IVH grade $\geq 3$ in the early 
extubation group was lower compared to those reported in the control group and in the latest nationwide survey (GA 25-26 weeks: $19.9 \%)^{34)}$.

Invasive mechanical ventilation is a major risk factor of $\mathrm{BPD}^{2)}$. The time on endotracheal ventilation in this present study was relatively shorter compared to those reported in previous studies ${ }^{6,12)}$. According to the latest nationwide survey ${ }^{35)}$, the combined rates of BPD or death were $68.7 \%$ at 25 weeks GA and $58.9 \%$ at 26 weeks GA. In the present study, the combined rate of clinical BPD or death was about $40 \%$. The duration of invasive ventilator use was a significant risk factor of ROP according to a latest nationwide survey ${ }^{36}$. The incidence of ROP requiring treatment in the early extubation group was higher than that in the control group, but relatively lower than that in the latest nationwide survey ${ }^{36)}$. However, no clear benefit was demonstrated for the use of synchronized NIPPV in terms of lowering the incidence rates of BPD or ROP. Further evidence of efficacy is needed.

Pneumoperitoneum as a complication of barotrauma is a rare condition resulting from mechanical ventilation ${ }^{37)}$. It is interesting that pneumoperitoneum without bowel perforation developed in two infants who were receiving synchronized NIPPV. In a previous study, gastric perforation developed in neonates who were receiving NIPPV ${ }^{38)}$. However, intestinal perforation was not associated with NIPPV use in the other studies ${ }^{9-13,16)}$. Further studies are needed to clarify whether pneumoperitoneum is a complication of nasal respiratory support.

Massive pulmonary hemorrhage within the first 5 days of life is a major cause of early death in ELBW ${ }^{39,40)}$. In this study, massive pulmonary hemorrhage developed in two infants who were receiving synchronized NIPPV, which led to their deaths. However, no clear evidence shows that nasal respiratory support increases the risk of fatal massive pulmonary hemorrhage.

In conclusion, early extubation (within the first 24 hours of life) with synchronized NIPPV is safe and effective in the extremely premature infants born at 25-26 weeks' gestation, and does not indicate increased risks of extubation failure and other morbidities. The lack of a comparative investigation of episodes of apnea or bradycardia between the two groups is a limitation of this study. Further prospective studies, preferably largerscale randomized controlled trials that incorporate NIPPV and NCPAP comparisons, are needed to assess the effectiveness of synchronized NIPPV in extremely premature infants.

\section{REFERENCES}

1) Bancalari E, del Moral T. Bronchopulmonary dysplasia and surfactant. Biol Neonate 2001;80 Suppl 1:7-13.

2) Jobe AH. Animal models, learning lessons to prevent and treat neonatal chronic lung disease. Front Med (Lausanne) 2015; 2:49.

3) Van Marter LJ, Allred EN, Pagano M, Sanocka U, Parad R, Moore M, et al. Do clinical markers of barotrauma and oxygen toxicity explain interhospital variation in rates of chronic lung disease? Pediatrics 2000;105:1194-201.

4) Vanpée M, Walfridsson-Schultz U, Katz-Salamon M, Zupancic JA, Pursley D, Jonsson B. Resuscitation and ventilation strategies for extremely preterm infants: a comparison study between two neonatal centers in Boston and Stockholm. Acta Paediatr 2007;96:10-6.

5) Dani C, Bertini G, Pezzati M, Cecchi A, Caviglioli C, Rubaltelli FF. Early extubation and nasal continuous positive airway pressure after surfactant treatment for respiratory distress syndrome among preterm infants $<30$ weeks' gestation. Pediatrics 2004;113:e560-3.

6) Ramanathan R, Sekar KC, Rasmussen M, Bhatia J, Soll RF. Nasal intermittent positive pressure ventilation after surfactant treatment for respiratory distress syndrome in preterm infants $<30$ weeks' gestation: a randomized, controlled trial. J Perinatol 2012;32:336-43.

7) Bhandari V. Nasal intermittent positive pressure ventilation in the newborn: review of literature and evidence-based guidelines. J Perinatol 2010;30:505-12.

8) Davis PG, Lemyre B, de Paoli AG. Nasal intermittent positive pressure ventilation (NIPPV) versus nasal continuous positive airway pressure (NCPAP) for preterm neonates after extubation. Cochrane Database Syst Rev 2001:CD003212. doi:10.1002 /14651858.Cd003212.pub2.

9) Friedlich P, Lecart C, Posen R, Ramicone E, Chan L, Ramanathan R. A randomized trial of nasopharyngeal-synchronized intermittent mandatory ventilation versus nasopharyngeal continuous positive airway pressure in very low birth weight infants after extubation. J Perinatol 1999;19:413-8.

10) Barrington KJ, Bull D, Finer NN. Randomized trial of nasal synchronized intermittent mandatory ventilation compared with continuous positive airway pressure after extubation of very low birth weight infants. Pediatrics 2001;107:638-41.

11) Khalaf MN, Brodsky N, Hurley J, Bhandari V. A prospective randomized, controlled trial comparing synchronized nasal intermittent positive pressure ventilation versus nasal continuous positive airway pressure as modes of extubation. Pedia- 
trics 2001;108:13-7.

12) Kugelman A, Feferkorn I, Riskin A, Chistyakov I, Kaufman B, Bader D. Nasal intermittent mandatory ventilation versus nasal continuous positive airway pressure for respiratory distress syndrome: a randomized, controlled, prospective study. J Pediatr 2007;150:521-6.

13) Moretti C, Giannini L, Fassi C, Gizzi C, Papoff P, Colarizi P. Nasal flow-synchronized intermittent positive pressure ventilation to facilitate weaning in very low-birthweight infants: unmasked randomized controlled trial. Pediatr Int 2008; 50:85-91.

14) Kulkarni A, Ehrenkranz RA, Bhandari V. Effect of introduction of synchronized nasal intermittent positive-pressure ventilation in a neonatal intensive care unit on bronchopulmonary dysplasia and growth in preterm infants. Am J Perinatol 2006;23:233-40.

15) Bhandari V, Finer NN, Ehrenkranz RA, Saha S, Das A, Walsh MC, et al. Synchronized nasal intermittent positive-pressure ventilation and neonatal outcomes. Pediatrics 2009;124:51726.

16) Bhandari V, Gavino RG, Nedrelow JH, Pallela P, Salvador A, Ehrenkranz RA, et al. A randomized controlled trial of synchronized nasal intermittent positive pressure ventilation in RDS. J Perinatol 2007;27:697-703.

17) Shi Y, Tang S, Zhao J, Shen J. A prospective, randomized, controlled study of NIPPV versus nCPAP in preterm and term infants with respiratory distress syndrome. Pediatr Pulmonol 2014;49:673-8.

18) Kiciman NM, Andréasson B, Bernstein G, Mannino FL, Rich W, Henderson C, et al. Thoracoabdominal motion in newborns during ventilation delivered by endotracheal tube or nasal prongs. Pediatr Pulmonol 1998;25:175-81.

19) Moretti C, Gizzi C, Papoff P, Lampariello S, Capoferri M, Calcagnini $\mathrm{G}$, et al. Comparing the effects of nasal synchronized intermittent positive pressure ventilation (nSIPPV) and nasal continuous positive airway pressure (nCPAP) after extubation in very low birth weight infants. Early Hum Dev 1999;56:16777.

20) Aghai ZH, Saslow JG, Nakhla T, Milcarek B, Hart J, LawryshPlunkett R, et al. Synchronized nasal intermittent positive pressure ventilation (SNIPPV) decreases work of breathing (WOB) in premature infants with respiratory distress syndrome (RDS) compared to nasal continuous positive airway pressure (NCPAP). Pediatr Pulmonol 2006;41:875-81.

21) Lee HS, Min SR. Comparison of effectiveness of nasal continuous positive airway pressure and nasal intermittent positive pressure ventilation for the initial treatment of preterm respiratory distress syndrome: a prospective pilot study. Neonatal Med 2014;21:158-65.
22) Gwon M, Lee JJ, Kim SB, Park MS, Lee JH. A comparison of humidified high flow nasal cannula with bubble CPAP in very low birth weight infants. Neonatal Med 2013;20:422-7.

23) Kattwinkel J, Perlman JM, Aziz K, Colby C, Fairchild K, Gallagher J, et al. Part 15: neonatal resuscitation: 2010 American Heart Association guidelines for cardiopulmonary resuscitation and emergency cardiovascular care. Circulation 2010; 122:S909-19.

24) Sandri F, Plavka R, Ancora G, Simeoni U, Stranak Z, Martinelli $\mathrm{S}$, et al. Prophylactic or early selective surfactant combined with nCPAP in very preterm infants. Pediatrics 2010;125: e1402-9.

25) Papile LA, Burstein J, Burstein R, Koffler H. Incidence and evolution of subependymal and intraventricular hemorrhage: a study of infants with birth weights less than 1,500 gm. J Pediatr 1978;92:529-34.

26) Jobe AH, Bancalari E. Bronchopulmonary dysplasia. Am J Respir Crit Care Med 2001;163:1723-9.

27) Stefanescu BM, Murphy WP, Hansell BJ, Fuloria M, Morgan $\mathrm{TM}$, Aschner JL. A randomized, controlled trial comparing two different continuous positive airway pressure systems for the successful extubation of extremely low birth weight infants. Pediatrics 2003;112:1031-8.

28) Al Faleh K, Liew K, Anabrees J, Thevathasan K, Paes B. Success rate and neonatal morbidities associated with early extubation in extremely low birth weight infants. Ann Saudi Med 2011;31:577-80.

29) Perlman JM, McMenamin JB, Volpe JJ. Fluctuating cerebral blood-flow velocity in respiratory-distress syndrome. Relation to the development of intraventricular hemorrhage. N Engl J Med 1983;309:204-9.

30) Perlman JM, Goodman S, Kreusser KL, Volpe JJ. Reduction in intraventricular hemorrhage by elimination of fluctuating cerebral blood-flow velocity in preterm infants with respiratory distress syndrome. N Engl J Med 1985;312:1353-7.

31) Koksal N, Baytan B, Bayram Y, Nacarkucuk E. Risk factors for intraventricular haemorrhage in very low birth weight infants. Indian J Pediatr 2002;69:561-4.

32) Kaiser JR, Gauss CH, Pont MM, Williams DK. Hypercapnia during the first 3 days of life is associated with severe intraventricular hemorrhage in very low birth weight infants. J Perinatol 2006;26:279-85.

33) Thome UH, Genzel-Boroviczeny O, Bohnhorst B, Schmid M, Fuchs H, Rohde O, et al. Permissive hypercapnia in extremely low birthweight infants (PHELBI): a randomised controlled multicentre trial. Lancet Respir Med 2015;3:534-43.

34) Ahn SY, Shim SY, Sung IK. Intraventricular hemorrhage and post hemorrhagic hydrocephalus among very-low-birthweight Infants in Korea. J Korean Med Sci 2015;30:S52-8. 
35) Jo HS, Cho KH, Cho SI, Song ES, Kim BI. Recent changes in the incidence of bronchopulmonary dysplasia among verylow-birth-weight infants in Korea. J Korean Med Sci 2015;30: S81-7.

36) Hwang JH, Lee EH, Kim EA. Retinopathy of prematurity among very-low-birth-weight infants in Korea: incidence, treatment, and risk factors. J Korean Med Sci 2015;30:S88-94.

37) Martinez Banos A, Segura MD, Galicia Negrete H, Lozano Gonzalez CH. Massive pneumoperitoneum secondary to barotrauma in a newborn infant. Bol Med Hosp Infan Mex 1981;38:649-56.
38) Garland JS, Nelson DB, Rice T, Neu J. Increased risk of gastrointestinal perforations in neonates mechanically ventilated with either face mask or nasal prongs. Pediatrics 1985;76:40610.

39) Kim SY, Park JY, Lee JA, Choi CW, Kim EK, Kim HS, et al. Risk factor for massive pulmonary hemorrhage occurring during the first five days after birth in extremely low birth weight infants. Neonatal Med 2014;21:18-27.

40) Tagare A, Chaudhari S, Kadam S, Vaidya U, Pandit A, Sayyad MG. Mortality and morbidity in extremely low birth weight (ELBW) infants in a neonatal intensive care unit. Indian J Pediatr 2013;80:16-20. 